\begin{tabular}{|c|c|}
\hline Title & Enantioselective Borylative Dearomatization of Indoles through Copper(I) Catalysis \\
\hline Author(s) & Kubota, Koji; Hayama, Keiichi; Iwamoto, Hiroaki; Ito, Hajime \\
\hline Citation & $\begin{array}{l}\text { A ngewandte chemie international edition, 54(30), 8809-8813 } \\
\text { https://doi.org/10.1002/anie.201502964 }\end{array}$ \\
\hline Issue Date & $2015-06-20$ \\
\hline DOC URL & http:/hdl.handle.net/2115/62248 \\
\hline Rights & $\begin{array}{l}\text { This is the accepted version of the following article: A ngewandte Chemie International Edition July 20, 2015, 54(30), } \\
\text { pp.8809-8813, which has been published in final form at } \\
\text { http://onlinelibrary.wiley.com/doi/10.1002/anie.201502964/abstract. }\end{array}$ \\
\hline Type & article (author version) \\
\hline File Information & Ito-ACIE54(30).pdf \\
\hline
\end{tabular}

Instructions for use 


\title{
Enantioselective Borylative Dearomatization of Indoles through Copper(I) Catalysis
}

\author{
Koji Kubota, Keiichi Hayama, Hiroaki Iwamoto and Hajime Ito*
}

\begin{abstract}
The first enantioselective borylative dearomatization of a heteroaromatic compound has been achieved using a copper(I) catalyst and a diboron reagent. This reaction involves the unprecedented regio- and enantioselective addition of active borylcopper(I) species to indole-2-carboxylates, followed by the diastereoselective protonation of the resulting copper $(I)$ enolate to give the corresponding chiral indolines bearing consecutive stereogenic centers.
\end{abstract}

Aromatic compounds are ubiquitous in nature and readily available as synthetic materials. The enantioselective dearomatization reactions of heteroaromatic compounds are very powerful transformations because they can be used to provide direct access to a wide variety of chiral-saturated heterocycles, which are important components of pharmaceutical drugs and bioactive molecules. ${ }^{[1]}$ The development of new methods for the formation of consecutive stereogenic centers via the stereoselective dearomatization of multi-substituted aromatic compounds would also have important practical implications for the synthesis of natural products. $^{[2]}$

Enantioenriched organoboron compounds are recognized as useful chiral building blocks in synthetic chemistry because they can be readily applied to the stereospecific functionalization of stereogenic $\mathrm{C}-\mathrm{B}$ bonds. ${ }^{[3]}$ Considerable research efforts have recently been devoted to the development of new methods for the metal-catalyzed enantioselective hydro- and protoboration reactions of prochiral $\mathrm{C}=\mathrm{C}$ double bonds. ${ }^{[4,5]}$ Despite significant progress in this area, there have been no reports pertaining to the development of $\mathrm{C}-\mathrm{B}$ bond-forming dearomatization reactions. The lack of research in this area is most likely caused by the high energy barrier encountered during the dearomatization process. $^{[1]}$ The development of an enantioselective C-B bondforming dearomatization reaction would provide an attractive and complementary approach for the synthesis of complex, functionalized cyclic molecules in combination with the stereospecific transformation of a stereogenic C-B bond.

Ohmura et al. ${ }^{[6]}$ and Weetman et al..$^{[7]}$ independently reported the results of their pioneering studies towards the development of a borylative dearomatization reaction, where pyridines were subjected to a dearomative hydroboration reaction with pinacolborane in the presence of $\mathrm{Rh}(\mathrm{I})$ and $\mathrm{Mg}$ (II) catalysts. In 2014, Marks et al. ${ }^{[8]}$ reported the development of a similar reaction using $\mathrm{La}$ (III) as a catalyst. However, the authors of these studies were only able to demonstrate non-

[*] K. Kubota, K. Hayama, H. Hiroaki, Prof. Dr. H. Ito Division of Chemical Process Engineering, Graduate School of Engineering, Hokkaido University

Kita 13 Nishi 8 Kita-ku, Sapporo, Hokkaido 060-8628 (Japan) E-mail: hajito@eng.hokudai.ac.jp

Supporting information for this article is given via a link at the end of the document enantioselective N-B bond-forming dearomatization reactions. ${ }^{[9,10]}$

Herein, we report for the first time the development of a copper(I)-catalyzed reaction for the highly regio-, diastereo- and enantioselective $\mathrm{C}-\mathrm{B}$ bond-forming dearomatization of heteroaromatic compounds (Scheme 1 ). This reaction involves the unprecedented enantioselective addition of an active borylcopper(I) species to an indole-2-carboxylate 1, followed by the diastereoselective protonation of the resulting copper(I) enolate to give the corresponding enantioenriched chiral indoline derivative 3 with excellent diastereo- and enantioselectivities. The stereospecific oxidation of the chiral 3-borylindoline product $\mathbf{3}$ has also been demonstrated.

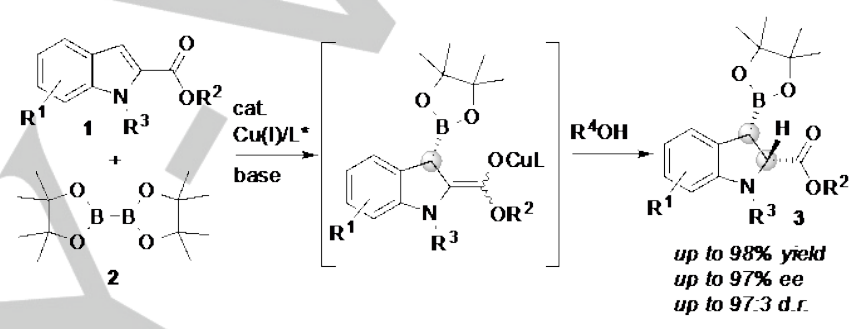

Scheme 1. Copper(I)-catalyzed diastereo- and enantioselective C-B bond forming dearomatization of indoles.

During the last decade, our group has been involved in the development of new methods for the copper(I)-catalyzed enantioselective borylation of prochiral alkenes. ${ }^{[11]}$ The results of the related research in this field revealed that electron-deficient substrates with low LUMO levels tend to react efficiently with active borylcopper(I) species. ${ }^{[12]}$ Based on these results, it was envisaged that heteroaromatic systems bearing an electronwithdrawing group could also react with a borylcopper(I) complex in a process involving the formation of a stereogenic $\mathrm{C}-\mathrm{B}$ bond. With this in mind, a readily available indole-2carboxylate derivative was selected as a model substrate to investigate the optimum reaction conditions for the enantioselective borylative dearomatization of this substrate using a chiral copper(I) catalyst. This reaction would allow for the synthesis of chiral indolines containing consecutive stereogenic centers at their 2- and 3-positions. Chiral indolines can be found in a wide variety of naturally occurring bioactive compounds and the synthesis of these compounds has consequently attracted considerable interest from researchers working in a number of different fields (Figure 1)..$^{[13,14]}$ The development of an enantioselective dearomative borylation reaction for indoles would therefore provide an interesting and efficient approach to this class of enantioenriched heterocycles.
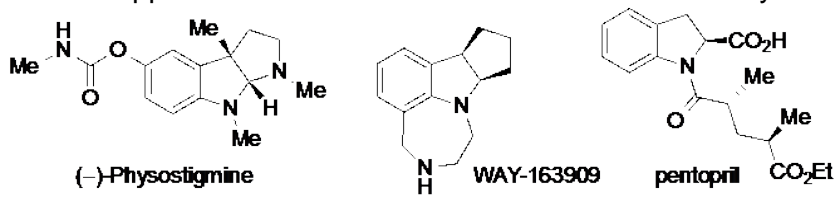

Figure 1. Chiral indoline-based bioactive molecules. 
The results of an extensive series of optimization experiments revealed that the reaction of carboxybenzyl (Cbz)protected methyl indole-2-carboxylate (1a) with bis(pinacolato)diboron (2) (2.0 equiv) in the presence of $\mathrm{Cu}(\mathrm{O}-\mathrm{t}$ $\mathrm{Bu}) /(R, R)-\mathrm{L} 1(10 \mathrm{~mol} \%), \mathrm{Na}(\mathrm{O}-t-\mathrm{Bu})(10 \mathrm{~mol} \%)$ and $t$-BuOH (2.0 equiv), which was used as a proton source, in THF at $30^{\circ} \mathrm{C}$ afforded the desired dearomatization product $(S, R)-3 \mathbf{a}$ in high yield (98\%), with excellent diastereo- and enantioselectivities (d.r. 97:3, 93\% ee) (Table 1, entry 1). ${ }^{[15]}$ Notably, no product was observed when the reaction was conducted in the absence of $\mathrm{Cu}(\mathrm{O}-\mathrm{t}-\mathrm{Bu}$ ) or ligand L1 (Table 1, entries 2 and 3). A lower yield $(74 \%)$ of the dearomatization product $\mathbf{3 a}$ was obtained when $\mathrm{Na}(\mathrm{O}-\mathrm{t}-\mathrm{Bu})$ was omitted from the reaction (Table 1, entry 4), although the omission of $t-\mathrm{BuOH}$ led to a significant decrease in the yield and stereoselectivity of the product (33\%, d.r. $76: 24$, $74 \%$ ee) (Table 1 , entry 5 ). The use of the less sterically hindered $(R, R)$-BDPP ligand $\mathbf{L} 2$ led to a lower enantioselectivity (74\% ee) (Table 1, entry 6$)$. Several other chiral bisphosphine ligands were also tested in the reaction, including $(R, R)$ QuinoxP* L3, $(R, R)$-BenzP* L4 and $(R, R)$-Me-Duphos L5, but they all showed poor stereoselectivities (Table 1, entries 7-9). No reaction was observed when the monophosphine-type chiral ligand $(R)$-MOP L6 was used in the reaction (Table 1, entry 10). A decrease in the loading of the catalyst to $5 \mathrm{~mol} \%$ did not lead to an erosion in the enantioselectivity (93\% ee), although slight decreases were observed in the product yield (76\%) and diastereoselectivity (d.r. 92:8) (Table 1, entry 11). The bulkiness of the alcohol was only found to affect the diastereoselectivity of this reaction, because the use of $\mathrm{MeOH}$ provided moderate diastereoselectivity (d.r. 75:25, Table1, entry 12).

Table 1. Copper(I)-catalyzed enantioselective $\mathrm{C}-\mathrm{B}$ bond-forming dearomatization of Indole $\mathbf{1} \mathbf{a}^{\text {[a] }}$
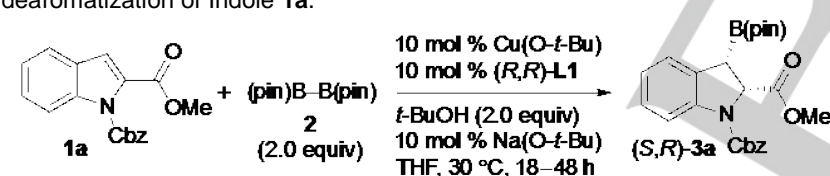

\begin{tabular}{|c|c|c|c|c|}
\hline entry & conditions & $\begin{array}{l}\text { yield } \\
{[\%]^{[b]}}\end{array}$ & d.r. ${ }^{[c]}$ & $\begin{array}{c}\mathrm{ee} \\
{[\%]^{[\mathrm{d}]}}\end{array}$ \\
\hline 1 & standard conditions & 98 & $97: 3$ & 93 \\
\hline 2 & no $\mathrm{Cu}(\mathrm{O}-t-\mathrm{Bu})$ & $<5$ & & - \\
\hline 3 & no $(R, R)-\mathbf{L} 1$ & $<5$ & & - \\
\hline 4 & no $\mathrm{Na}(\mathrm{O}-\mathrm{t}-\mathrm{Bu})$ & 74 & $89: 11$ & 93 \\
\hline 5 & no $t$-BuOH & 33 & $76: 24$ & 74 \\
\hline 6 & $(R, R)$-L2 instead of $(R, R)$-L1 & 98 & 89:11 & 74 \\
\hline 7 & $(R, R)$-L3 instead of $(R, R)$-L1 & 93 & $90: 10$ & 27 \\
\hline 8 & $(R, R)$-L4 instead of $(R, R)$-L1 & 77 & $91: 9$ & 61 \\
\hline 9 & $(R, R)$-L5 instead of $(R, R)$-L1 & 71 & $97: 3$ & 37 \\
\hline 10 & $(R)$-L6 instead of $(R, R)$-L1 & $<5$ & - & - \\
\hline 11 & $5 \mathrm{~mol} \%$ of $\mathrm{Cu}(\mathrm{O}-\mathrm{t}-\mathrm{Bu}) /(R, R)-\mathrm{L} 1$ & 76 & $92: 8$ & 93 \\
\hline
\end{tabular}

12

$\mathrm{MeOH}$ instead of $t$ - $\mathrm{BuOH}$

94

$75: 25$

94

[a] Reactions were performed with $1 \mathbf{a}(0.5 \mathrm{mmol}), \mathrm{Cu}(\mathrm{O}-\mathrm{t}-\mathrm{Bu})(0.05 \mathrm{mmol})$, chiral ligand (0.05 mmol), bis(pinacolato)diboron 2 (1.0 mmol), Na(O-t-Bu) $(0.05 \mathrm{mmol})$ and alcohol $(1.0 \mathrm{mmol})$ in THF $(1.0 \mathrm{ml})$, unless stated otherwise in the table. [b] Determined by ${ }^{1} \mathrm{H}$ NMR analysis of the crude reaction mixture with an internal standard. [c] Determined by ${ }^{1} \mathrm{H}$ NMR analysis of the crude reaction mixture. [d] Determined by HPLC analysis.
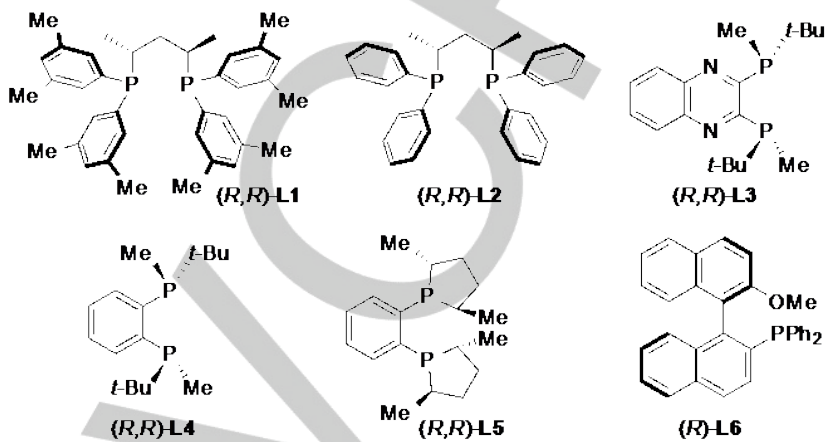

With an optimized procedure in hand, we proceeded to investigate the scope of the reaction using a variety of indole substrates (Table 2). The introduction of an electron-withdrawing or electron-donating functional group at the 5-position of the indole was well tolerated, with the borylation reaction affording consistently excellent selectivities (3b-e). Indoles bearing a bromo, methoxy or phenyl substituent at their 6-position also reacted with high levels of stereoselectivity (3f-h). The borylation of an indole bearing an ethyl ester group (3i) proceeded with high enantioselectivity (95\% ee), but with a lower product yield (52\%). The borylation of an indole bearing a bulky isopropyl ester group (1j) failed to provide any of the desired product $(S, R)-\mathbf{3} \mathbf{j}$ under the optimized conditions. Fortunately, the replacement of $(R, R)$-L1 with $(R, R)-\mathrm{L} 2$ allowed for the borylation of $\mathbf{1} \mathbf{j}$ to proceed in good yield (88\% NMR) and excellent stereoselectivity (d.r. 95:5, 90\% ee). We subsequently proceeded to investigate the scope of the protecting group on the indole. The borylation of tert-butyloxycarbonyl (Boc)protected indole $\mathbf{1 k}$ provided the expected product $(S, R)$-3k with the highest enantioselectivity ( $98 \%$ ee) observed in the current study, although the yield was significantly decreased (22\% NMR). The replacement of $(R, R)-\mathbf{L} 1$ with the less sterically hindered $(R, R)$-L2 led to a significant improvement in the yield (98\% NMR) with good stereoselectivity (d.r. 93:7, 86\% ee). Unfortunately, the application of the optimized conditions to a fluorenylmethyloxycarbonyl (Fmoc)-protected indole group failed to provide any of the desired product, presumably because of the reaction of the acidic proton of the Fmoc group with $\mathrm{Na}(\mathrm{O}-\mathrm{t}$ $\mathrm{Bu})$, which resulted in the formation of a complex mixture. We also found that Me-protected indoles were not applicable to this protocol.

Table 2. Substrate scope. ${ }^{[a, b]}$ 

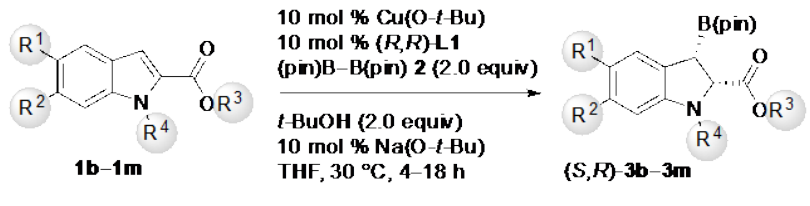

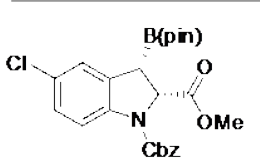

$(S, R)-3 \mathbf{b}$

$64 \%\{93 \%)$

d.r. $937,95 \%$ ee<smiles>COC(=O)[C@H]1[C@H]([18OH])c2cc(OC)ccc2N1C(=O)OC</smiles>

$$
(S, R)-3 \mathrm{e}
$$

$74 \%\{99 \%)$ d.r. $97-3,97 \%$ ee

B(pin)<smiles>COC(=O)[C@@H]1[C@H]([18OH])c2ccc(-c3ccccc3)cc2N1C(=O)OCc1ccccc1</smiles>

(S,R)-3h

$71 \%(82 \%)$ d. $83: 17,89 \%$ ee<smiles>COC(=O)[C@H]1[C@H](Br)c2ccccc2N1C(=O)OC(C)(C)C</smiles>

$\{S, R)-3 k$

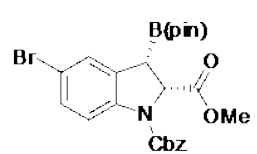

$\mathrm{Cbz}$

$(S, R)-3 c$ $74 \%(96 \%)$ d. $97,3,92 \%$ ee

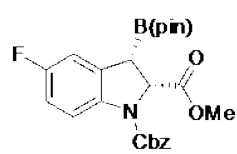

(S,R)-3d $74 \%$ (93\%) d.r. $97-3,95 \%$ ee B(pin)

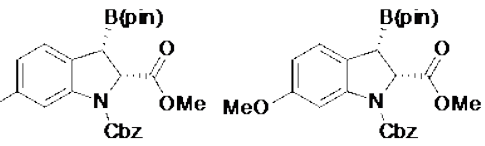

$\mathrm{Cbz}$
$(S, R)-3 \mathrm{~g}$ $76 \%(88 \%)$ $76 \%(88 \%)$
d.r. $946,93 \%$ ee B(pn) $62 \%(99 \%)$ d.r. $93: 7,86 \%$ ee B(pin)<smiles>CCOC(=O)[C@H]1[C@@H](C)c2ccccc2N1C(=O)OCc1ccccc1</smiles><smiles>CC(C)OC(=O)[C@@H]1Cc2ccccc2N1C(=O)OCc1ccccc1</smiles>

Cbz

$$
(S, R)-3 \mathrm{j}[\mathrm{kl}
$$

$67 \%(88 \%)$ d.r. $95: 5,90 \%$ ee $52 \%(55 \%)$
d. $86: 14,95 \%$ ee

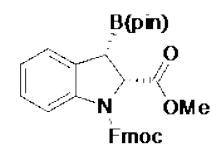

$(S, R)-31$

(S,R)-31

<5\%) ligand: $(R, R)<1$ ligand: $(R, R) L$

$13 \%(22 \%) \quad 95 \%(98 \%)$

d.r. $946,98 \%$ ee d.r. $93: 7,86 \%$ ee

[a] Conditions: $\mathrm{Cu}(\mathrm{O}-\mathrm{t}-\mathrm{Bu})(0.05 \mathrm{mmol}),(R, R)-\mathrm{L} 1(0.05 \mathrm{mmol}), 1$ (0.5 $\mathrm{mmol})$, bis(pinacolato)diboron $2(1.0 \mathrm{mmol}), \mathrm{Na}(\mathrm{O}-\mathrm{t}-\mathrm{Bu})(0.05 \mathrm{mmol})$ and $t$ $\mathrm{BuOH}(1.0 \mathrm{mmol})$ in THF $(1.0 \mathrm{~mL})$. [b] Isolated yields. NMR yields are shown in parentheses. [c] $(R, R)$-L2 was used instead of $(R, R)$-L1.

The chiral borylation product $(S, R)$-3d generated in this study was subjected to an oxidation reaction, where it was treated with $\mathrm{NaBO}_{3}$ followed by a silyl protection reaction to give the desired chiral 1,2-aminoalcohol $(S, R)-4$ in a highly stereoselective manner (d.r. $>99: 1,94 \%$ ee, Scheme 2). It is noteworthy that it would not be possible to synthesize this product using existing dearomative oxidation methods. ${ }^{[16]}$

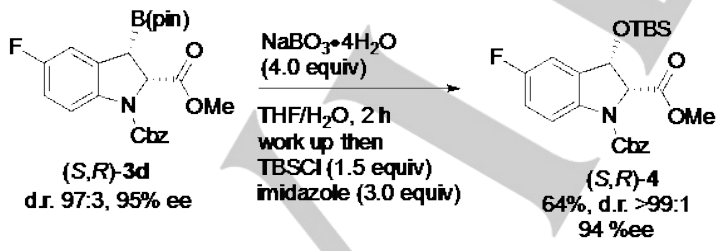

Scheme 2. Stereospecific oxidation of chiral 3-borylindoline $(S, R)-3 \mathbf{d}$.

The enantioselective borylation of the 2-methyl indole that does not contain an ester group (10) resulted in no reaction (Scheme 3a). ${ }^{[17]}$ Preliminary density functional theory (DFT) calculation (B3PW91/cc-pVDZ) was used to explain the effect of substituents at the 2-position in the substrate (Scheme $3 b) .{ }^{[18]}$ The results show that the LUMO level of $1 \mathrm{a}(-1.51 \mathrm{eV})$ was considerably lower than the LUMO+1 level of $10(-0.68 \mathrm{eV})$, which is localized in the reactive site, indicating that the electron- withdrawing ester moiety would facilitate the addition of borylcopper $(\mathrm{I})$ intermediate to the indoles.

a)

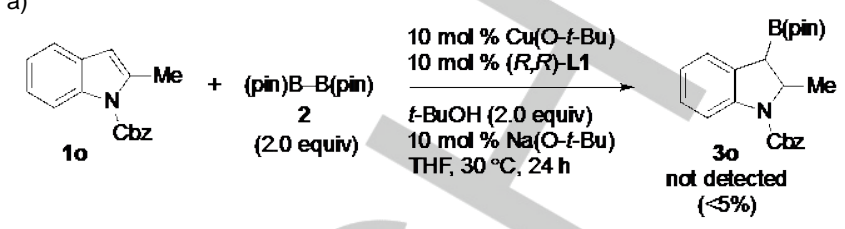

b)

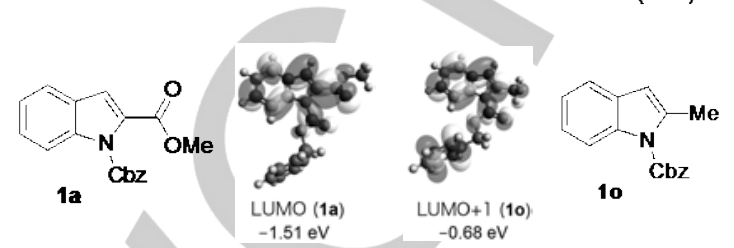

Scheme 3. a) Borylative dearomatization of Cbz-protected 2-methyl indole 10 b) The reactive vacant orbital levels of 19 and 10 (B3PW91/cc-pVDZ)

A mechanism was proposed for the current copper(I)catalyzed dearomative borylation of indoles (Figure 2a). Cu(O-t$\mathrm{Bu}) \mathrm{A}$ would initially react with diboron reagent 2 to form the borylcopper(I) B. The coordination of indole $\mathbf{1 a}$ to the copper center would result in the formation of $\pi$-complex $\mathbf{C}$. The subsequent 3,4-addition of $\mathbf{B}$ into 1a would give the copper(I) C enolate and then transform to the $O$-enolate $\mathbf{D}$ with concomitant formation of a stereogenic C-B bond ${ }^{[18]}$ After the formation of $\mathbf{D}$, the bulky $t-\mathrm{BuOH}$ additive would access $\mathrm{D}$ from the opposite side of the pinacolate boryl group to avoid steric congestion between the $\mathrm{B}$ (pin) and $t$-Bu groups. The subsequent diastereoselective protonation of $\mathbf{D}$ would proceed via a sixmembered ring transition state $\mathbf{E}$ to provide the dearomatization product $(S, R)-3 \mathbf{a}$ and the $\mathrm{Cu}(\mathrm{O}-t-\mathrm{Bu})$ precatalyst $\mathbf{A}$.

A preliminary DFT calculation (B3PW91/cc-pVDZ) was performed to elucidate the mechanism of the dearomatization step in this reaction (Figure $2 b$ ). ${ }^{[18]}$ The results showed that the activation energy for the addition of borylcopper(I) I to indole II to furnish the copper(I) C-enolate IV was $+18.0 \mathrm{kcal} / \mathrm{mol}$, which was in agreement with the proposed pathway (Figure 2a). ${ }^{[18]}$

a)

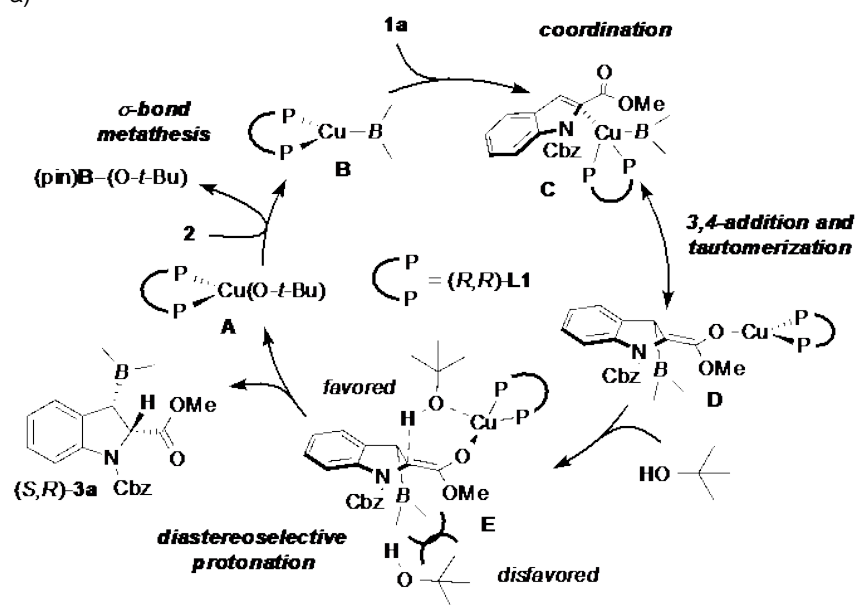

b) 


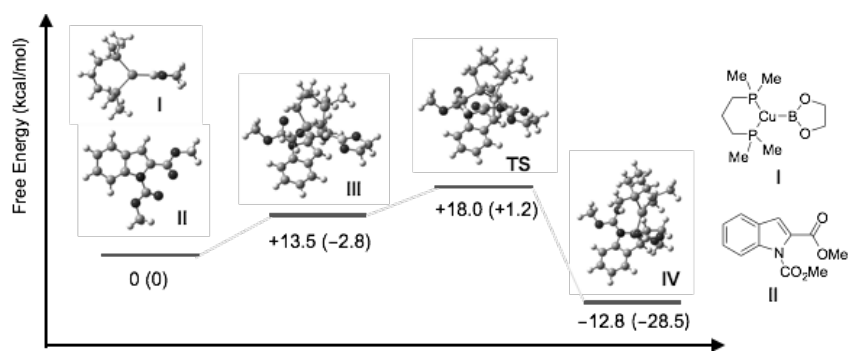

Figure 2. a) Proposed catalytic cycle. b) DFT calculation (B3PW91/cc-pVDZ) of the dearomative insertion step. Relative $G$ value $(\mathrm{kcal} / \mathrm{mol})$ at $298 \mathrm{~K}, 1.0$ atm gas phase. Electronic energies are shown in parentheses.

In summary, we have developed the first enantioselective $\mathrm{C}-\mathrm{B}$ bond-forming dearomatization of heteroaromatic compound using a chiral bisphosphine-copper(l) complex catalyst and a diboron reagent. This reaction involved the unprecedented enantioselective dearomative addition of borylcopper(I) to methyl indole-2-carboxylate with concomitant formation of a stereogenic $\mathrm{C}-\mathrm{B}$ bond, followed by the diastereoselective protonation of the copper(I) enolate intermediate to deliver the enantioenriched chiral indoline bearing consecutive stereogenic centers with excellent regio-, diastereo- and enantioselectivities. It is envisaged that the results of this study will provide further opportunities for the development of novel stereoselective dearomative borylation reactions involving a wide variety of aromatic compounds, such as pyrroles, furans and polyaromatic hydrocarbons. Advances in this area would therefore allow for the efficient synthesis of complex saturated heterocyclic compounds with potentially interesting biological activities.

\section{Acknowledgements}

This work was financially supported by the MEXT (Japan) program [Strategic Molecular and Materials Chemistry through Innovative Coupling Reactions] of Hokkaido University. This work was also supported by JSPS KAKENHI Grant Number 15H03804 and 15K13633.K.K. would like to thank JSPS for scholarship support.

Keywords: $\bullet$ borylation $\cdot$ copper catalyst $\bullet$ enantioselective synthesis $\cdot$ dearomatization $\bullet$ indole

[1] For a review of catalytic enantioselective dearomative transformations, see: a) C. -X. Zhuo, W. Zhang, S. -L, You, Angew. Chem. Int. Ed. 2012, 51, 12662-12686; b) Q. Ding, X. Zhou, R. Fan, Org. Biomol. Chem. 2014, 12, 4807-4815; c) C. -X. Zhuo, C. Zheng, S. -L, You Acc. Chem. Res. 2014, 47, 2558-2573.

[2] For a review concerning the application of dearomatization strategies to the synthesis of natural products, see: a) S. P. Roche, J. A. Porco, Jr., Angew. Chem. Int. Ed. 2011, 50, 4068-4093.

[3] a) D. G. Hall, Boronic Acids: Preparation and Applications in Organic Synthesis, Medicine and Materials, 2nd revised Ed, Wiley- $\mathrm{VCH}$ Weinheim, 2011; b) S. N. Mlynarski, C. H. Schuster, J. P. Morken Nature 2014, 505, 386-390; c) M. Burns, S. Essafi, J. R. Bame, S. P. Bull, M. P. Webster, S. Balieu, J. W. Dale, C. P. Butts, J. N. Harvey, V. K. Aggarwal, Nature 2014, 513, 183-188.

[4] For selected examples of the rhodium(I)-catalyzed enantioselective hydroboration reactions, see: a) T. Hayashi, Y. Matsumoto, Y. Ito, J. Am. Chem. Soc. 1989, 111, 3426-3428; b) C. M. Crudden, Y. Hleba, A. Chen, J. Am. Chem. Soc. 2004, 126, 9200-9201.
[5] For selected examples of the copper(I)-catalyzed enantioselective protoboration reaction, see: a) V. Lillo, A. Prieto, A. Bonet, M. M. Diaz Requejo, J. Ramirez, P. J. Pérez, E. Fernández, Organometallics 2009, 28, 659-662; b) Y. Lee, A. H. Hoveyda, J. Am. Chem. Soc. 2009, 131 3160-3161; c) D. Noh, H. Chea, J. Ju, J. Yun, Angew. Chem. Int. Ed. 2009, 48, 6062-6064; d) J. C. H. Lee, R. McDonald, D. G. Hall, Nat Chem. 2011, 3, 894-899; e) Z. T. He, Y. S. Zhao, P. Tian, C. C. Wang, H. Q. Dong, G. Q. Lin, Org. Lett. 2014, 16, 1426-1429; f) A. Parra, L. Amenós, M. Guisán-Ceinos, A. López, J. L. G. Ruano, M. Tortosa, J. Am. Chem. Soc. 2014, 136, 15833-15836; g) H. Lee, B. Y. Lee, J. Yun Org. Lett. 2015, 17, 764-766.

[6] K. Oshima, T. Ohmura, M. Suginome, J. Am. Chem. Soc. 2012, 134 3699-3702.

[7] M. Arrowsmith, M. S. Hill, T. Hadlington, G. Kociok-Kohn, C. Weetman, Organometallics 2011, 30, 5556-5559.

[8] A. S. Dudnik, V. L. Weidner, A. Motta, M. Delferro, T. J. Marks, Nat. Chem. 2014, 6, 1100-1107.

[9] For a report concerning the palladium-catalyzed non-enantioselective silaborylative dearomatization of pyridines, see: K. Oshima, T. Ohmura, M. Suginome, J. Am. Chem. Soc. 2011, 133, 7324-7327.

[10] For a report concerning an organocatalytic N-B bond-forming dearomatization, see: T. Ohmura, Y. Morimasa, M. Suginome, J. Am. Chem. Soc. 2015, 137, 2852-2855.

[11] For selected examples of copper(I)-catalyzed enantioselective borylation reactions from our group, see: a) H. Ito, S. Ito, Y. Sasaki, K Matsuura, M. Sawamura, J. Am. Chem. Soc. 2007, 129, 14856-14857; b) Y. Sasaki, C. Zhong, M. Sawamura, H. Ito, J. Am. Chem. Soc. 2010 132, 1226-1227; c) H. Ito, S. Kunii, M. Sawamura, Nat. Chem. 2010, 2, 972-976; d) K. Kubota, E. Yamamoto, H. Ito, Adv. Synth. Catal. 2013 355, 3527-3531; e) E. Yamamoto, Y. Takenouchi, T. Ozaki, T. Miya, H. Ito, J. Am. Chem. Soc. 2014, 136, 16515-16521.

[12] For experimental and theoretical studies on the copper(I)-catalyzed borylation of activated alkenes, see: a) D. S. Latitar, E. Y. Tsui, J. P. Sadighi, Organometallics 2006, 25, 2405-2408; b) L. Dang, H. Zhao, Z. Lin, T. B. Marder, Organometallics 2007, 26, 2824-2832. c) L. Dang, Z. Lin, T. B. Marder, Organometallics 2008, 27, 4443-4454.

[13] a) S. Kobayashi, G. Peng, T. Fukuyama, Tetrahedron Lett. 1999, 40 1519-1522; b) J. L. Pinder, S. M. Weinreb, Tetrahedron Lett. 2003, 44, 4141-4143; c) D. Crich, A. Banerjee, Acc. Chem. Res. 2007, 40, 151161; d) Y. Sasaki, D. Kato, D. L. Boger, J. Am. Chem. Soc. 2010, 132, 13533-13544.

[14] For review and selected examples of the synthesis of the indoline scaffold, see: a) W. Zi, Z. Zuo, D. Ma, Acc. Chem. Res. 2015, 48, 702711; b) R. Kuwano, K. Sato, T. Kurokawa, D. Karube, Y. Ito, J. Am. Chem. Soc. 2000, 122, 7614-7615.

[15] Diastereomeric ratio values of the products were determined by ${ }^{1} \mathrm{H}$ NMR analysis of the crude reaction mixture. The minor diastereome could be completely separated by silica gel column chromatography. The ee values were determined by HPLC analysis of the isolated products. The configuration of the borylation product was determined by NOE analysis of $(S, R)$-3a and X-ray crystallographic analysis of the oxidation product $(S, R)-5$ derived from $(S, R)-3 \mathbf{c}$. The details have been provided in the Supporting Information.

[16] F. Kolundzic, M. N. Noshi, M. Tjandra, M. Movassaghi, S. Miller, J. Am. Chem. Soc. 2011, 133, 9104-9111.

[17] 2-Methyl indole was selected as a substrate to avoid deprotonation at the 2-position by $\mathrm{Na}(\mathrm{O}-t-\mathrm{Bu})$. We also confirmed that the borylation of non-substituted $\mathrm{Cbz}$-protected indole resulted in no reaction.

[18] Although the current substrate is aromatic indole-2-carboxylate, we found that $\mathrm{C} 2-\mathrm{C} 3$ double bond makes a higher contribution than that of carbonyl moiety in the LUMO orbitals, indicating the boryl cupration of the indoles would proceed via 3,4-addition pathway in a similar manner to the borylation of $\alpha, \beta$-unsaturated carbonyl compounds (ref. 12). The details have been provided in the Supporting Information. 


\section{COMMUNICATION}

The enantioselective borylative dearomatization of methyl indole-2-carboxylate using a copper(I) catalyst and a diboron reagent afforded chiral 3-borylindoline derivatives with excellent regio-, diastereo- and enantioselectivities. The products of this reaction could be transformed to the corresponding chiral 1,2aminoalcohol with high stereospecificity.

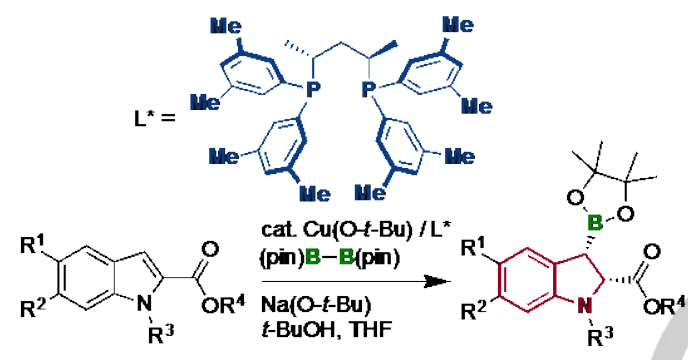

Koji Kubota, Keiichi Hayama, Hiroaki, Iwamoto, Hajime Ito*

Page No. - Page No.

Enantioselective Borylative Dearomatization of Indoles using Copper(I) Catalysis

- the first enantioselective borylative dearomatization

- excellent regio-, diastereo-, and enantioselectivity 